PNL-6920

UC-95a

\title{
Review of Second Law Analysis \\ Techniques Applicable to the \\ Energy Conversion and \\ Utilization Technologies Thermal \\ Science Program
}

M. K. Drost

J. R. Zaworski

June 1989

Prepared for the U.S. Department of Energy

under Contract DE-AC06-76RLO 1830

Pacific Northwest Laboratory

Operated for the U.S. Department of Energy

by Battelle Memorial Institute 


\title{
DISCLAIMER
}

This program was prepared as an account of work sponsored by an agency of the United States Government. Neither the United States Government nor any agency thereof, nor Battelle Memorial Institute, nor any of their employees, makes any warranty, express or implied, or assumes any legal liability or responsibility for the accuracy, completeness, of usefulness of any information, apparatus, product, or process disclosed, or represents that its use would not infringe privately owned rights. Reference herein to any specific commerical product, process, or service by trade name, trademark, manufacturer, or otherwise, does not necessarily constitute or imply its endorsement, recommendation, or favoring by the United States Government or any agency thereof, or Battelle Memorial Institute. The views and opinjons of authors expressed herein do not necessarily state or reflect those of the United States Government or any agency thereot.

\section{PACIFIC NORTHWEST LABORATORY operated by \\ BATTELLE MEMORIAL INSTITUTE for the \\ UNITED STATES DEPARTMENT OF ENERGY under Contract DE-AC06-76RLO 1830}

\author{
Printed in the United States of America \\ Available from \\ National Technical information Service \\ United States Oepartment of Commerce \\ 5285 Port Royal Road \\ Spring fiełd, Virginia 22161 \\ NTIS Price Codes \\ Microfiche A01 \\ Printed Copy
}

$\begin{array}{cc}\text { Pages } & \begin{array}{c}\text { Price } \\ \text { Codes } \\ 001-025\end{array} \\ 026-050 & \text { A02 } \\ 051-075 & \text { A03 } \\ 076-100 & \text { A04 } \\ 101-125 & \text { A05 } \\ 126-150 & \text { A06 } \\ 751-175 & \text { A07 } \\ 176-200 & \text { A08 } \\ 201-225 & \text { A09 } \\ 226-250 & \text { A70 } \\ 251-275 & \text { A11 } \\ 276-300 & \text { A12 }\end{array}$


REVIEW OF SECOND LAW ANALYSIS TECHNIQUES APPLICABLE TO THE ENERGY CONVERSION AND

UTILIZATION TECHNOLOGIES

THERMAL SCIENCES PROGRAM

M. K. Drost

J. R. Zaworski

June 1989

Prepared for the U.S. Department of Energy under Contract DE-AC06-76RLO 1830

Pacific Northwest Laboratory

Richland, Washington 99352 


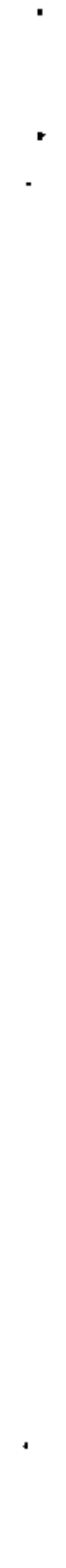




\section{SUMMARY}

Second law analysis techniques are becoming increasingly popular for the evaluation of thermodynamic processes and systems. These techniques have in common an assessment of the quality of energy streams. While second law analysis has been widely used to evaluate and optimize components and systems of components, its role in a basic thermal sciences program is not clear. The U.S. Department of Energy's Energy Conversion and Utilization Technologies Program supports a basic research program in the themal sciences.

This study was conducted in 1987 by Pacific Northwest Laboratory (a) for the Energy Conversion and Utilization Technology Program to determine whether second law techniques can be used in guiding or contributing to basic research in the thermal sciences. The study consisted of an extensive but not comprehensive literature review (approximately 300 references were included) followed by the preparation of a draft report. Second law techniques identified by the literature review were organized into five categories: system optimization studies, system investigations, component optimization studies, component investigations, and differential analysis. A draft report was prepared and reviewed by nationally recognized experts in second law analysis.

The study concluded that second law analysis can contribute to basic thermal science research by providing program guidance and by directly contributing to the research. System and component investigations can provide program guidance by supplying information on the cause and location of irreversibilities. Differential analysis of local entropy generation can contribute directly to thermal science research by providing information on the causes and spatial and temporal distribution of local irreversibilities. This information will provide an enhanced understanding of fluid mechanics, thermodynamics, and heat and mass transfer, and may suggest innovative methods of reducing irreversibility.

(a) Operated by Battelle Memorial Institute for the U.S. Oepartment of Energy under Contract DE-AC06-76RLO 1830. 
The major recommendation resulting from the study is that a finite difference code should be developed for calculating local irreversibility by determining local entropy generation. This would allow the application of the differential approach to complicated geometries. 


\section{ACKNOWLEDGMENTS}

The authors wish to acknowledge the Energy Conversion and Utilization Technologies Program of the U.S. Department of Energy for supporting this work. In addition, the authors acknowledge the reviews conducted by $\mathrm{Dr}$. Reistad of Oregon State University, Dr. Gaggioli of the University of Lowell, and Dr. Bejan of Duke University. 



\section{CONTENTS}

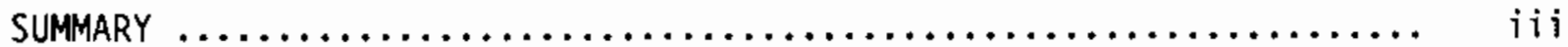

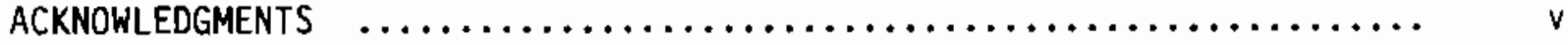

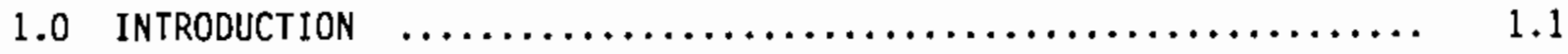

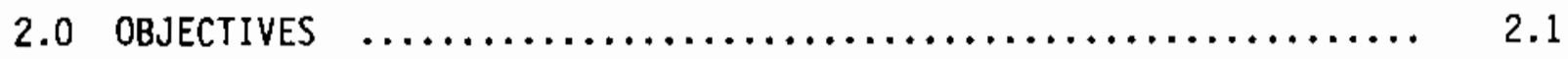

3.0 OUTLINE OF SECOND LAW ANALYSIS TECHNIQUES $\ldots \ldots \ldots \ldots \ldots \ldots \ldots . . . \ldots \ldots$

3.1 RELATIONSHIP BETWEEN SECOND LAW ANALYSIS AND

TRADITIONAL ANALYSIS $\ldots \ldots \ldots \ldots \ldots \ldots \ldots \ldots \ldots \ldots, \quad 3.1$

3.2 CALCULATION OF IRREVERSIBILITY $\ldots \ldots \ldots \ldots \ldots \ldots \ldots \ldots \ldots, 3.2$

3.3 SECOND LAW TECHNIQUES AND APPLICATIONS $\ldots \ldots \ldots \ldots \ldots \ldots \ldots . . .4$

3.3.1 System Optimization Studies $\ldots \ldots \ldots \ldots \ldots \ldots \ldots \ldots . . .6 . .4$

3.3 .2 System Investigations $\ldots \ldots \ldots \ldots \ldots \ldots \ldots \ldots \ldots \ldots, 3.6$

3.3.3 Component Optimization Studies $\ldots \ldots \ldots \ldots \ldots \ldots \ldots . . .6$

3.3 .4 Component Investigations $\ldots \ldots \ldots \ldots \ldots \ldots \ldots \ldots, 3.7$

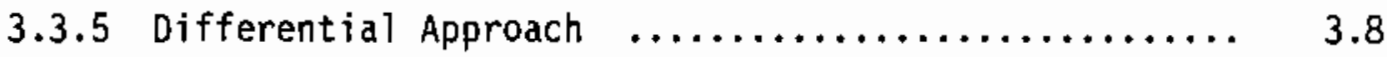

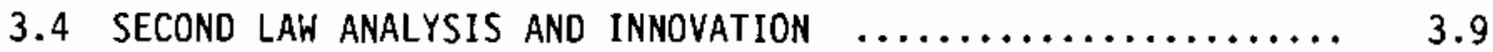

4.0 SECOND LAW APPLICATIONS IN BASIC THERMAL SCIENCES RESEARCH $\ldots \ldots .4 .1$

4.1 ROLE OF SECOND LAW ANALYSIS IN GUIDING BASIC THERMAL

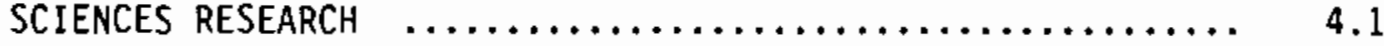

4.2 ROLE OF SECOND LAW ANALYSIS IN CONTRIBUTING TO THERMAL

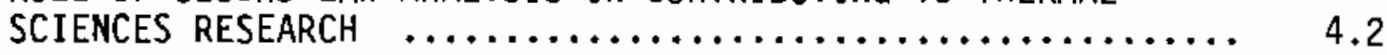

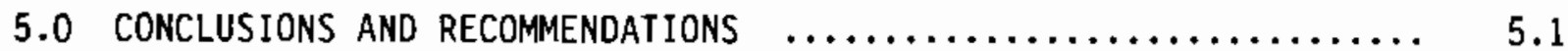

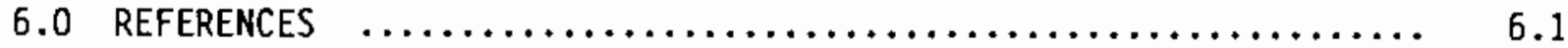





\subsection{INTRODUCTION}

This report describes a review of second law analysis emphasizing techniques applicable to basic research in the thermal sciences. Second law analys is is a class of thermodynamic analysis techniques that has become increasingly popular in the design of thermal systems. Pacific Northwest Laboratory (a) conducted this review in 1987 for the U.S. Department of Energy's (DOE) Energy Conversion and Utilization Technologies (ECUT) Program. The primary goal is to determine whether second law techniques can be used in guiding or contributing to basic research in the thermal sciences.

The mission of the ECUT Program is to develop the baseline generic data needed by designers to develop new energy conversion technologies. The ECUT Thermal Sciences Program has a specific set of goals including:

- Provide a comprehensive technology data base for the design and development of energy conversion and heat and mass transfer systems and devices.

- Develop and apply new experimental and analytical techniques to enhance the understanding of fluid mechanics, thermodynamics, and heat and mass transfer processes.

- Identify and examine the technological feasibility of advanced and innovative energy conversion and heat transfer concepts.

Second law analys is can potentially contribute to the ECUT Thermal Sciences Program in two ways. Programmatic guidance can be provided by identifying key problems and evaluating ongoing research. Second law analysis may also contribute directly to the enhancement of the understanding of basic phenomena in the thermal sciences.

(a) Operated by Battel le Memorial Institute for the U.S. Department of Energy under Contract DE-AC06-76RLO 1830.

(b) In this report, basic research in the thermal sciences means investigations of fundamental fluid dynamic, heat transfer, and thermodynamic processes on a cycle, component, or process level. This is not meant to suggest that other thermodynamic research is not "basic" but only that it is not within the scope of this program. 
The method used in this review consisted of an extensive but not comprehensive literature review (approximately 300 references were included) followed by the preparation of a draft report. The draft was then sent to nationally recognized experts in second law analys is for technical review and comment. This report has been rewritten to reflect many of the reviewer's comments. 


\subsection{OBJECTIVES}

The primary objective of this study is to review second Taw analytical techniques and identify techniques that may provide information useful for directing the ECUT Thermal Sciences Program. A second objective is to identify second law techniques that may contribute directly to the themal sciences research tasks. Both of these objectives are discussed below in more detail. This review is required because second law analysis has not been widely used in basic thermal sciences research and the potential benefits of such an approach have not been previously assessed.

The first objective of this study is to see if second law analys is can provide new information that will influence the direction of basic thermal science research. It is hoped that second law analysis can provide improved understanding related to at least some of the following questions:

- Which components or processes in existing or proposed energy conversion and heat transfer concepts are significant sources of losses, what mechanisins cause these losses, and are they intrinsic or $c$ an the losses be reduced by further research?

- Are there innovative(a) solutions or new approaches for dealing with major loss mechanisins?

- Which advanced energy conversion and heat transfer concepts are attractive and should be pursued?

- Are existing basic thermal science research projects successfully attacking key problems?

- What new thermal sciences research should be initiated?

The second goal is to detemine where second law analysis can contribute directly to the ECUT Thermal Sciences Program, particularly in enhanced

(a) For this paper innovation implies a new or original solution to a problem. Innovation can include: new devices, a new arrangement of existing devices, new processes or new operating strategies. Optimization of an existing arrangement of existing components, while important, would not be considered innovation. 
understanding of fluid mechanics, themodynamics, heat and mass transfer processes, or analysis of advanced or innovative energy conversion and heat transfer concepts. 


\subsection{OUTLINE OF SECOND LAW ANALYSIS TECHNIQUES}

Second law analys is techniques have in common an assessment of the quality of energy streams and may include evaluations of the degradation of the quality of energy that takes place in all real processes. The fundamentals of second law analys is are discussed in numerous references (Gaggioli 1983; Bejan 1982) and will not be repeated here. Instead, the main objective of this chapter is to present a method of classifying second law techniques. The classification has been arranged to help identify second law techniques that may be useful in basic thermal science research. Section 3.1 describes the relationship between second law analysis and more traditional analytical techniques. Section 3.2 presents the two methods of determining irreversibility, while Section 3.3 discusses the actual classification scheme. Section 3.4 describes how second law analysis can contribute to innovation.

\subsection{RELATIONSHIP BETWEEN SECOND LAW ANALYSIS AND TRADITIONAL ANALYSIS}

The second law has always played a key role in themodynamic analysis. Traditional analytical techniques rely on the second 1 aw to evaluate the performance of complex systems (Van Wylen and Sonntag 1973). During the 1970s and 1980 s a series of explicit "second law" analytical techniques was being investigated. These techniques often determined a property, such as exergy or availability, that identified the quality of an energy flow or reservoir. Traditional techniques could identify energy flow losses but could not explicitly quantify the quality of the various energy flows. The new explicit second law techniques could analyze both energy losses and the degradation of the quality of energy. With these advances, second law techniques have been successful in clearly identifying the true sources of themodynamic losses.

Second law analysis can be viewed as an extension of traditional techniques. Most second law studies begin with a mass, monentum, and energy balance. The second law component of the study then assigns a "quality" figure of merit to the various flows. Therefore, it is not correct to compare second law analysis to first law analysis because any second law study will rely 
heavily on results from the application of the conservation equations to the problem of interest. It would be more accurate to describe the new explicit second law techniques as "combined" analysis. However, to avoid further proliferation of terms (in a field already overloaded with terminology) we will use "second law analysis."

The relationship between second 1 aw analysis and traditional techniques emphasizes another characteristic of second law analysis. Second law analysis depends on traditional analysis to provide the themal and flow characteristics of a process. In general, second law analysis, particularly local analysis of processes, can be no better than the understanding of the underlying heat transfer, mass transfer, and fluid dynamics.

Because traditional analysis does use the second law, traditional analysis has often been successful in identifying the same system and component improvements that would come from a second law analysis. This has led many observers to the conclusion that second law analysis does not provide anything new. Based on our literature review and contacts with experts in second law analysis, our conclusion is that second law analysis does provide new information and enhances the ability of the analyst to identify innovative solutions to thermal science problems. When compared to traditional analysis, second law analysis accurately identifies the true sources of thermodynamic losses. This information, when presented in a usable manner, will direct the analyst to the major losses and will identify the sources of the losses.

\subsection{CALCULATION OF IRREVERSIBILITY}

Most second law methods either explicitly or implicitly involve identification (and hopefully minimization) of irreversibilities in a system or component. Therefore, the identification of irreversibilities is the fundamental step in most second law methods. There are two ways in which irreversibilities can be identified: the exergy (a) balance approach and an approach based on the Gouy-Stodola relationship (8ejan 1982).

(a) Exergy may be defined as a measure, expressed in tems of work, of the capacity of a given form of energy to cause change (Kotas 1986). 
The exergy balance approach consists of defining a control volume and summing the exergy flows into and out of the control volume. If the flows are steady (no accumulation of exergy in the control volume, and if all processes taking place in the control volume are reversible, the total exergy inflow due to work and heat interactions and mass flows will equal the total exergy outflow in work and heat interactions and mass flows. Real processes must be, to some extent, irreversible (i.e.., exergy is destroyed in the process). In this case, the outflow of exergy will be less than the inflow, and the irreversibility of the process can be calculated using Equation (3.1) (again assuming steady flows).

$$
\text { Irreversibility }=\text { (total exergy inflow) - (total exergy outflow) }
$$

The exergy balance approach can be used on both the macroscopic and differential scale. As a tool for fundamental themal science investigations, the application of the exergy balance approach on the macroscopic scale can have limited usefulness because this approach cannot identify the source of the irreversibility in the control volume if more than one source of irreversibility is present.

An alternative approach is to use the Gouy-Stodola relationship given in Equation (3.2):

$$
\text { Irreversibility }=T_{0} \text { (entropy generation rate) }
$$

where $T_{0}$ is the absolute temperature of the appropriate environment. The total entropy generation rate can be a sum of several entropy generation rates where each is associated with a specific source of irreversibility. Entropy generation can often be calculated from first principles, thus allowing an accurate determination of the source mechanism, spatial distribution, and temporal distribution of irreversibility in a thermal process. In a similar manner. the exergy balance approach can be applied on the local level to deternine the location and sources of irreversibilities. 


\subsection{SECOND LAH TECHNIQUES AND APPLICATIONS}

Once irreversibilities have been identified, this information can be used either explicitly or implicitly with a number of second law analysis techniques. The major applications for second law analysis are discussed below. This taxonomy of applications presents our impressions of previous second law investigations and is based on a broad but not exhaustive literature review. The purpose is to emphasize second law techniques that are applicable to basic thermal sciences research.

\subsubsection{System Optimization Studies}

Probably the most widespread use of second law analysis is in optimizing systems of components with known performance and cost characteristics. The goal is to improve the system performance by determining the optimum sizing of system components rather than identifying new and innovative components or processes.

The optimization of heat exchanger networks is a good example of system optimization studies. The problem is to identify the optimum heat exchanger network to produce a specified number of product streams, given the source streams. Several explicit or implicit second law procedures for optimizing a network of heat exchangers are described in the literature (Linnhoff 1986; Pehler and Liu 1983; Floudas and Grossman 1986). (a) These procedures identify optimum arrangements and sizes of the heat exchangers in the network. One technique known as "pinch technology" has been used in over 500 applications with dramatic cost benefits over conventional techniques (Linnhoff and Ahmad 1986). These procedures successfully improve the cost and performance of heat exchanger networks, which is their intended purpose, but they do not offer guidance on improving the design of individual heat exchangers or support innovative improvements of the process.

(a) References to examples of the various types of second law analys is are included in the relevant sections. In general, recent references are presented. This tends to underrepresent the contribution of many second Taw researchers, particularly early contributors such as Dr. Gaggioli, Dr. Bejan, Dr. Reistad, Dr. Evans, Dr. Tribus, and many others. 
Most applications of themoeconomics also concentrate on optimizing systems of known components. In these investigations, the purpose of the optimization is to identify a system with the optimum (least cost) balance between capital costs and exergy costs. In a review of second law techniques, Kotas (1986) described the advantages of using second law methods of thermoeconomics optimization:
"The advantage of using themoeconomic optimization is that the various elements of the system can be optimized on their own, the effect of the interaction between the given element and the whole system being taken into account by local unit costs of exergy flows or those of exergy losses. The individual optimization of system elements is made possible in these methods because of the universality of exergy as a standard of quality of energy and the availability of the concept of irreversibility rate as a measure of process imperfection."

A large number of thermoeconomic studies are described in the literature. Several representative examples include thermoeconomic analysis of integrated coal-gasification combined cycle power plants (Tsatsaronis and Winhold 1986), thermoeconomic analysis of heat exchange networks (Hesselmann 1986) and the themoeconomic analysis of an air separation plant (Knoche and Hesselmann 1986). In addition, one group has proposed a general theory of thermoeconomic analysis (Tsatsaronis and Winhold 1985).

System optimization techniques are becoming an established and useful application of second law analysis. In addition to improving a design, an optimization study can educate the analyst about the sources of irreversibility that may ultimately lead to innovative design changes. While being useful in many areas, these techniques concentrate on aptimizing systems of existing components. Therefore, they will probably not prove to be as useful as other second law techniques in either planning or conducting the ECUT research program in the basic thermal sciences. (a)

(a) This is not to suggest that research on complex systems and systems optimization is not basic research, but, rather, that it is outside the scope of the ECUT Thermal Sciences Program. 


\subsubsection{System Investigations}

This type of investigation is simitar to the system optimization in that a systern of known components is analyzed but in this case the system is not optimized. Instead, the system is investigated with the objective of determining the principal sources of system irreversibilities and losses with the hope that by knowing the source of system irreversibilities, the system can be improved. Improvements can include new arrangements, improved sizing of existing components, new components, or the identification of components or processes with opportunities for substantial improvements.

Studies vary widely in scope and methodology. Both the exergy balance and Gouy-Stodola approach have been used to evaluate irreversibilities (Bejan 1982). often the results consist of thermodynamic calculations for the system, with a final calculation of an overall themodynamic figure of merit (second law efficiency). Occasionally, cost factors are included in the analysis procedure.

A few recent examples of system investigations include second law analysis of absorption cycle heat pumps (Bosnjakovic et al. 1986; Herold and Moran 1985; . Anand et al. 1984), coal gasification (Gaggioli and Wepfer 1980), total energy plants (Gaggioli et al. 1985), combined power and desalination plant (Gaggioli et al. 1986), wood-fired combined cycle power plants (Bushnell et al. 1985) and solar domestic hot water heating systems (Gaggioli 1985). In general, system investigations analyze exergy flows, sources of irreversibility, and conversion figures of merit.

System investigations can be useful in identifying sources of irreversibility and in presenting system performance in a theoretically sound fashion, but this type of analysis has seldom been used to identify innovative system improvements. Often the system improvements identified by second law analysis are also identified by conventional analytical techniques. This issue is discussed in Section 3.4 .

\subsubsection{Component Optimization Studies}

Component optimization studies consist of second law investigations with the goal of optimizing an individual component, such as a heat exchanger or compressor. A wide range of second law techniques has been used for component 
optimization. Irreversibilities have been determined using both the exergy balance approach applied to regions of the component and the Gouy-Stodola relationship. Most often, optimum designs have been determined based on a thermodynamic figure of merit; occasionally, however, thermoeconomic techniques have been used in component optimization studies.

Under the topic of component optimization, several noteworthy studies will be described. Although many of these studies have been conducted and reviewed, we will mention component optimization studies of particular interest to basic thermal science research. Bejan has developed optimization techniques for a variety of components, particularly heat exchangers (Bejan 1977, 1979b). In these studies, entropy generation (and consequently irreversibilities) are minimized in the subject component. London and Shah (1983) assign a cost to heat exchanger irreversibilities and present a method of producing an economic optimum design. Both first law and second law optimizations of sensible heat themal storage units using themodynamic figures of merit were conducted by Taylor (1986). Other typical component investigations include analysis of solar receivers (Moynihan 1983), ammonia reactors (Mansson and Andreson 1986) and compact heat exchangers (Tapia and Moran 1986). These evaluations are useful in providing a clear understanding of the true tradeoffs in the thermal design of a component. Although component optimization studies can identify sources of irreversibility, this information has rarely been used to target research or suggest innovative methods of reducing irreversibility. In general, component optimization consists of optimizing an existing design rather than exploring alternatives and is, therefore, of less usefulness to the ECUT Thermal Sciences Program than are other second law techniques.

\subsubsection{Component Investigations}

In component investigations a component with known characteristics is analyzed, but not analytically optimized. Instead, the component is investigated with the objective of determining the principal sources of the component's irreversibility. It is hoped that, with this knowledge, the component can be improved.

A few recent examples of component investigations include evaluations of diesel engines (Primus and Flynn 1986), thermal energy storage units 
(Mathiprakasam and Beeson 1983) and gas turbines (El-Masri 1985). This type of study can use either the exergy balance or Gouy-Stodola approach to determine irreversibilities. Often the results consist of themodynamic calculations for the component with a final determination of an overall thermodynamic figure of merit.

The main difference between the component optimization and the component investigation is the optimization procedure. Being able to analytically optimize a component implies that the performance is sufficiently understood to be modeled mathematically. The component investigation is less restricted because an optimization is not being attempted. Although the ultimate goal of component development is to reach a level of understanding that would allow optimization studies, a basic research effort is probably dealing with issues that are not sufficiently understood to permit optimization.

As with system investigations, component investigations can identify the sources of irreversibility in a component, but this approach has seldom been used to identify innovative component improvements. When improvements are identified, it is not clear that the second law analysis has provided any new information that could not have come from conventional analytical techniques. The role of second law analysis in innovation and its relationship to traditional techniques is discussed in Section 3.4 .

\subsubsection{Differential Approach}

The differential approach to second law analysis is a method of analysis rather than an application. It consists of using the Gouy-Stodola relationship to determine local irreversibility from the local production of entropy. Irreversibility in the regions of interest can then be determined if the appropriate information is available throughout the region. This approach was developed by Bejan for the evaluation of entropy generation in fundamental convective heat transfer (Bejan 1979a). Bejan has used the differential approach to evaluate internal flow (Bejan 1979b), insulation systems (Bejan 1979c) and heat exchangers (Bejan 1978). Hutchinson and Lyke (1987) have also used the differential approach to analyze oscillating flow in regenerative heat exchangers. 
The differential approach gives detailed information on the fundamental mechanisms causing the irreversibility and the spatial and temporal distribution of the irreversibility generation. Previous investigations, excluding that of Hutchinson and Lyke (1987), have been limited to geometric and fluid flow cases where exact analytical solutions exist.

As with other second Taw techniques, the differential approach has generally been used to analyze or optimize performance of existing designs rather than to use the information on irreversibility generation to suggest new designs or lines of research. There are, however, several examples where this approach has identified innovative solutions to thermal design problems. Bejan's analysis of insulation systems (1979C) showed that there is an optimum heat flow distribution through an insulating system, which minimizes entropy generation. To attain this distribution, intermediate heating or cooling may be required. This approach to insulation design is new and would have come only from a second law analysis. A second example of a successful application of the differential approach is the work by Hutchinson and Lyke (1987). This study includes the first published analytical rationale for axially nonuniforin regenerators in Stirling cycle heat engines. It is unlikely that the advantages of axial nonuniformity would have been identified using traditional analytical methods. The differential approach has not been applied as widely as other techniques. Our literature review indicated perhaps 10 to 15 papers on this subject, compared to more than 700 on other second law subjects (Kotas 1986).

\subsection{SECOND LAW ANALYSIS AND INNOVATION}

As indicated in Section 3.3, the literature review did not identify many situations where second law studies resulted in innovation.(a) Critics of second law analysis have used this to suggest that explicit second law analysis techniques are not needed. In this section we will discuss the usefulness of second law analysis as a tool for encouraging innovation.

(a) This observation does not apply to optimization studies, in which it appears that second $l$ aw and related techniques are estabilished and successful. 
As with any analytical technique, second law analysis is not an "engine of innovation." The application of second law analysis for any other analytical method) to a problem will not automatically result in innovation. In all cases, innovation comes from the analyst. When second law analys is is compared with traditional analytical approaches, the key issue is related to which approach will best inform and motivate the analyst to be innovative. In our opinion, second law analysis clearly does the better job of informing and motivating the analyst. This is true for several reasons:

- identification of losses - Second law analysis clearly and accurately identifies components and processes with high losses. Traditional methods do not properly assign losses. The classic example is combustion, which has a high first law efficiency but which is actually highly irreversible. In this case, and in many other cases, the traditional approach gives an inaccurate picture of thermodynamic losses. This can only inhibit innovation because the innovator cannot properly identify the problem.

- identification of loss mechanisms - In addition to identifying the location of losses, second law can accurately identify the sources of the losses. Again, combustion is the classic example. Traditional analysis suggests that heat in the flue gas from a power plant is the main loss mechanism associated with combustion; second law analysis shows that the major irreversibilities are due to the uncontrolled combustion of the fuel and heat transfer across a finite temperature difference (Gaggioli 1983). Lack of accurate information on the sources of losses must tend to inhibit innovation.

Given these advantages, why hasn't second law analysis proved to be more successful in innovation? First, many practitioners of second law analysis would disagree with the suggestion that second law analysis has not been successful in innovation because many innovations, such as regenerative feedwater heaters and fuel cells, are the result of second law thinking but not "explicit" second law techniques. Second, it is our opinion that many second law investigations have not sufficiently emphasized using the results for innovation. 
In conclusion, no analytical technique is innovative--only the analyst is innovative; however, because second law analysis most clearly identifies the location and source of losses, it is most likely to inform and motivate the analyst. The innovations discussed in Section 3.3 .5 resulted from this approach. To maximize the benefit of second law analysis, one goal of second law research should be to develop techniques that help the analyst visualize irreversibilities and evaluate the impact of design changes on thermodynamic losses. 
. 


\subsection{SECOND LAW APPLICATIONS IN BASIC THERMAL SCIENCES RESEARCH}

When the second law techniques are reviewed in light of the objectives of this study, it is clear that only a small number of second law analysis studies and techniques are relevant to a basic thermal sciences research program. System and component optimization studies are useful in optimizing a known design but are not intended to suggest new lines of investigation. As discussed in Section 3.4, second law analysis is most useful in identifying the location and sources of irreversibilities and in presenting this infomation to the analyst. System and component evaluations and the differential approach seem to offer the best means for identifying and presenting useful information to an analyst working in basic thermal sciences research. In this section we will first discuss the contributions that second law andysis can make in guiding basic themal sciences research. Second, the possibility for a direct second law contribution to themal sciences research will be discussed.

\subsection{ROLE OF SECOND LAW ANALYSIS IN GUIDING BASIC THERMAL SCIENCES RESEARCH}

Guiding research includes two activities: identification of new research topics and the evaluation of new and existing research. Two second law analytical techniques may make useful contributions to both activities:

- system and component evaluations - As described in Section 3.0, system and component evaluations can identify sources of irreversibility in advanced and innovative energy conversion and heat transfer concepts. This infomation may be useful in targeting research on highly irreversible components and processes. This would be a useful tool for assisting an analyst in identifying new research topics and could be used for evaluating the attractiveness of new concepts and processes. In addition, second law analysis can suggest the maximum possible improvement in a process or component. This capability may be useful in selecting research with a high potential payoff. The problem with this approach is that many systems and component evaluations have been conducted with the intent of identifying improvements. While parametric improvements have often resulted, we have 
found little evidence of innovative new technology. Rather, second law analysis can only point to where the new technology is needed. Greater emphasis should be placed on using the results of system and component evaluations for such research guidance.

- differential approach - The differential approach can also be used to identify and evaluate new and existing research. The differential approach can provide information on the different local irreversibility rates in thermal processes of interest, and can show which irreversibilities can be traded off against one another. This knowledge would be useful in identifying the true sources of local irreversibility, determining the maximum possible improvements in a process or component, and potentially suggesting new lines of research. The differential approach would complement macroscopic analysis by providing a tool for the analysis of local phenomena and their interactions, thus getting closer to the root causes of the irreversibility.

In addition to the two main options listed above, specific questions of interest to decision makers may require other approaches. Consequently, it may be necessary to have a variety of second law techniques available.

\subsection{ROLE OF SECOND LAW ANALYSIS IN CONTRIBUTING TO THERMAL SCIENCES RESEARCH}

In addition to guiding basic thermal sciences research, second law analysis can make a direct contribution to the actual research. In particular, the differential approach has the potential to provide new insights in fluid dynamics, thermodynamics, and in fundamental heat and mass transfer processes. The suggested approach is to use differential analysis as embodied in a finite difference computer code to analyze irreversibility generation in a variety of situations. Initially, irreversibility in flowing fluids would be analyzed. This would involve irreversibility caused by heat transfer across finite temperature differences, mixing of fluids with different pressures or temperatures, and viscous dissipation. The procedure could be later extended to include irreversibilities in reacting flows so that local irreversibilities associated with chemical reactions could be investigated. Irreversibilities 
related to mass transfer can also be included, thus creating a tool for investigation of mixing and separation problems. The results of these evaluations would consist of a predicted source of irreversibility along with its spatial and temporal distribution in the thermal process of interest. This information can be presented to the analyst in a variety of forms including a visual presentation where an irreversibility generation graphic presentation would play a role similar to stress concentration graphics resulting from finite element stress analysis. This type of information should materially assist the analyst in identifying innovative methods of reducing irreversibilities.

In a similar manner, entropy calculations can be added to multiphase multicomponent finite difference computer codes to analyze irreversibilities in multiphase and multicomponent flows. Our literature review has not identified previous investigations of entropy generation in multiphase flows. Therefore, this application may require original research to establish the proper relationships for entropy generation in multiphase flows.

For many applications, one-dimensional analysis, such as that used by Hutchinson and Lyke (1987) and Dunbar (1982) may be more appropriate. Hutchinson and Lyke divided a Stirling engine regenerator into several zones and calculated irreversibilities for each zone using previously developed data on pressure drops and flow fields. This approach avoids having to solve the mass and momentum equations as part of the irreversibility analysis, but it is dependent on having appropriate data available. Dunbar used a one-dimensional model to analyze irreversibilities in a fuel cell.

In sumnary, the differential approach would provide a new analytical technique for understanding thermal phenomena (ECUT Goal 2) and could be used to evaluate process irreversibilities associated with advanced and innovative energy conversion and heat transfer concepts (ECUT Goal 3). Although it is clearly feasible to determine local irreversibility generation (which is of intrinsic interest on its own), it is hoped that detailed knowledge of local irreversibility will motivate the innovative scientist/engineer to suggest new methods for reducing irreversibility. 



\subsection{CONCLUSIONS AND RECOMMENDATIONS}

Based on our review of second law analytical techniques for possible application to the ECUT Thermal Sciences Program, we have drawn the following conclusions :

- program guidance - System and component investigations using either the exergy balance or Gouy-Stodola relationship for determining irreversibilities can provide infomation on the cause and location of irreversibilities on a macroscopic scale. The differential approach will provide similar information on local irreversibilities. This information will help to identify new research topics and allow evaluation of existing and proposed research.

- program contribution - The differential approach can provide information on the causes and spatial and temporal distribution of local irreversibilities. This information will provide an entanced understanding of fluid mechanics, thermodynamics, and heat and mass transfer, and may suggest innovative methods of reducing irreversibility.

- expected results - Although we can say with confidence that second law techniques can identify macroscopic and local irreversibility, it is not certain that this knowledge will be crucial. It is expected that it will motivate the analyst to identify innovative approaches to reducing irreversibility, although this cannot be guaranteed. We recommend the ECUT Program to take the following actions:

- Select sample applications from the ECUT Thermal Sciences Program for second law analysis using both system investigations and the differential approach.

- Develop a finite difference computer code for calculating irreversibilities using the differential approach. This would allow the application of the differential approach to complicated geometries and flow situations. It appears that this can be done relatively easily for single-phase flows by including irreversibility 
calculations in an existing fluid mechanics finite difference computer code, such as TEMPEST. Multiphase flows may require more extensive theoretical analysis but existing multiphase codes are available for modification.

- Use a "nested" approach to second law analysis. Several of the experts contacted during the review phase of this study suggested that the most effective use of second law techniques would consist of using several "nested" investigations. A system investigation can be used to target highly irreversible components, which can then be investigated on a more detailed level using a component investigation. Finally, irreversible processes can be investigated using the differential approach.

- Where appropriate, involve second law analysis experts in the program. Our interviews with second law experts proved to be enlightening and useful. Clearly, this source of expertise should be used by the program.

- Keep abreast of the substantial second law work being done outside the United States. 


\section{REFERENCES}

Anand, D. K., K. W. Lindler, S. Schweitzer, and W. J. Kennish. 1984. "Second Law Analys is of Solar Powered Absorption Cooling Cycles and Systems." J. Solar Energy Engineering 106:291-298.

Bejan, A. 1977. "The Concept of Irreversibility in Heat Exchanger Design: Counterflow Heat Exchangers for Gas-to-Gas Applications." J. Heat Transfer $99: 374-380$.

Bejan, A. 1978. "General Criterion for Rating Heat Exchanger Performance." Int1. J. of Heat and Mass Transfer 21:655-658.

Bejan, A. 1979a. "A Study of Entropy Generation in Fundamental Convective Heat Transfer." J. Heat Transfer 101:718-725.

Bejan, A. 1979b. "Second Law Analysis in Heat Transfer." Presented at Workshop on "The Second Law of Thermodynamics," held at George washington University, Washington, D.C., August 14-16, 1979.

Bejan, A. 1979c. "A General Variational Principle for Thermal Insulation System Design." Intl. J. of Heat and Mass Transfer 22:219-228.

Bejan, A. 1982. Entropy Generation Through Heat and Fluid Flow. Wiley Interscience, New York, New York.

Bosnjakovic, K. F., K. F. Knoche, and D. Stehmeier. 1986. "Exergetic Analysis of Amnonia/Water Absorption Heat Pumps." In Computer Aided Engineering of Energy Systems, Vol. 2.3 - Second Law Analys is and Modeling. American Society of Mechanical Engineers, New York, New York.

Bushnell, D. J., G. M. Reistad, T. Bauer, S. Brynjolfsson, and S. Fox. 1985. "First and Second Law Evaluation of Wood-Fired Combined Cycle Power Plants." In Analys is of Energy Systems - Design and Operation. American Society of Mechanical Engineers, New York, New York.

Dunbar, W. R. 1982. Computer Simulation of a High Temperature Solid Electrolyte Fuel Cel1. M.S. Thes is, Marquette University, Milwaukee, Wisconsin.

El-Masri, M. A. 1985. "Thermodynamics of Gas Turbine Cycles: Part 2 - Second Law Analys is of Combined Cycles." $\mathrm{J}$. Eng. for Gas Turbines and Power, Vol. 107, October 1985.

Floudas, C. A., and I. E. Grossman. 1986. "Automatic Synthes is of Flexible Heat Exchanger Network Configurations for Multi-period Operation." In Computer Aided Engineering of Energy Systems, Vol.2.1 - Optimization. American Society of Mechanical Engineers, New York, New York. 
Gaggioli, R. A. 1983. "Second Law Analysis for Process and Energy Engineering." In Efficiency and Costing, Second Law Analysis of Processes. ACS 235, American Chemical Society, Washington, D.C.

Gaggioli, R. A., W. Ling, and J. R. Too. 1985. "Second Law Analysis of a Total Energy Plant." In Analysis of Energy Systems - Design and Operation. American Society of Mechanical Engineers, New York, New York.

Gaggioli, R. A. 1985. "Second Law Analysis of a Solar Domestic Hot Water Heating System." In Analys is of Energy Systems - Design and Operation. American Society of Mechanical Engineers, New York, New York.

Gaggioli, R. A., Y. M. El-Sayed, A. M. El-Nashar, and B. Kamaluddin. 1986. "Second Law Efficiency and Costing Analysis of Combined Power and Desalination Plant." In Computer Aided Engineering of Energy Systems, Vol . 2.3 - Second Law Analys is and Modeling. American Society of Mechanical Engineers, New York, New York.

Gaggioli, R. A., and W. J. Wepfer. 1980. "Second Law Costs Applied to Coal Gasification." Coal Processing Technology. Vol. VI, American Institute of Chemical Engineers, New York, New York.

Herold, K. E., and M. J. Moran. 1985. "A Themodynamic Investigation of an Absorption Temperature Boosting Heat Pump." In Analysis of Energy Systems Design and Operation. American Society of Mechanical Engineers, New York, New York.

Hesselmann, K. 1986. "Heat Exchanger Networks, An Exergoeconomic Evaluation." In Computer Aided Engineering of Energy Systems, Vol. 2.3 - Second Law Analysis and Modeling. American Society of Mechanical Engineers, New York, New York.

Hutchinson, R. A., and S. E. Lyke. 1987. "Microcomputer Analys is of Regenerative Heat Exchangers for 0scillating Flows." In Proceedings of the 1987 ASME/JSME Thermal Engineering Joint Conference, Vol. 2, $\rho p .653$. American Society of Mechanical Engineers, New York, New York.

Knoche, K. F., and K. Hesselmann. 1986. "Exergoeconomical Analys is of Chemical Processes-Evaluation of an Air Separation." In Computer Aided Engineering of Energy Systems, Vol. 2.3 - Second Law Analys is and Modeling. American Society of Mechanical Engineers, New York, New York.

Kotas, T. J. 1986. "Exergy Method of Thermal and Chemical Plant Analysis." Chem. Eng. Res. Des. 64:212-229 (May).

Linnhoff, B. 1986. "Pinch Technology for the Synthesis of Optimal Heat and Power Systems." In Computer Aided Engineering of Energy Systems, Vol. 2.1 Optimization. American Society of Mechanical Engineers, New York, New York. 
Linnhoff, B., and S. Ahmad. 1986. "Supertargeting: Optimum Synthesis of Energy Management Systems." In Computer Aided Engineering of Energy Systems, Vol. 2.1 - Optimization. American Society of Mechanical Engineers, New York, New York.

London, A., and R. K. Shah. 1983. "Cost of Irreversibilities in Heat Exchanger Design." Heat Transfer Eng., Vol. 4, No. 2.

Mansson, B., and B. Andresen. 1986. "Optimal Temperature Profile for an Ammonia Reactor." Ind. Eng. Chem. Process Des. Dev. 25:59-65.

Mathiprakasam, B., and J. Beeson. 1983. "Second Law Analys is of Thermal Energy Storage Devices." In Heat Transfer. ACE 225, Vol. 79, American Institute of Chemical Engineers, New York, New York.

Moynihan, P. I. 1983. Second Law Efficiency of Solar-Thermal Cavity Receivers. DOE/JPL-1060-65, Jet Propulsion Laboratory, Pasadena, California.

Pehler, E. A., and Y. A. Liu. 1983. "Thermodynamic Availability Analys is in the Synthes is of Optimum-Energy and Minimum-Cost Heat Exchanger Networks." In Efficiency and Costing. ACS 235, American Chemical Society, New York, New York.

Primus, R. J., and P. F. Flynn. 1986. "The Assessment of Losses in Diesel Engines Using Second Law Analys is." In Computer Aided Engineering of Energy Systems, Vol. 2.3 - Second Law Analysis and Modeling. American Society of Mechanical Engineers, New York, New York.

Tapia, C. F., and M. J. Moran. 1986. "Efficiency Compact Heat Exchangers A Thermoeconomic Perspective." In Advancing Toward Technology Breakout in Energy Conversion. Proceedings of the 21st Intersociety Energy Conversion Engineering Conference, Vol. 1, pp. 22. American Chemical Society, Washington, D.C.

Taylor, M. J. 1986. Second Law Optimization of a Sensible Heat Thermal Energy Storage System with Distributed Storage Element. ORNL/TM-10054, 0ak Ridge National Laboratory, Oak Ridge, Tennessee.

Tsatsaronis, G., and M. Winhold. 1985. "Exergoeconomic Analys is and Evaluation of Energy Conversion Plants - I, A New General Method." Energy 10(1):6985.

Tsatsaronis, G., and M. Winhold. 1986. "Exergoeconomic Analysis of an Integrated Coal Gasification-Combined-Cycle Power Plant." In Computer Aided Engineering of Energy Systems, Vol. 2.3 - Second Law Analys is and Modeling. American Society of Mechanical Engineers, New York, New York.

Van Wylen, J. G., and R. E. Sonntag. 1973. Fundamentals of Classical Thermodynamics. John Wiley and Sons, Inc., New York, New York. 



\section{DISTRIBUTION}

No. of

Copies

OFFSITE

U.S. Department of Energy

Attn: M. Gunn

Energy Conversion and Utilization Technology Program

ForrestaT Bidg., CE-12 5E-066

Washington, DC 20585

10 DOE/Office of Scientific and

Technical Information

Argonne National Laboratory

Attn: Mr. Tony Thomas

g700 South Cass Ave.

Argonne, IL 60439

Astronautics Corp. of America

Attn: John Barclay

Astronautics Technology Center

5800 Cottage Grove Rd.

Madison, WI 53716

Duke University

Attn: Dr. Adrian Bejan

Department of Mechanical Eng.

and Material Science

Durham, NC 27706

Dr. R. A. Gaggioli

391 High Street

Westwood, MA 02090

Idaho National Engineering Lab.

Attn: Dr. Jim Mills

PO Box 1625

Idaho Falls, ID 83415

Mississippi State University

Attn: Dr. G. A. Adebiyi

Mechanicat and Nuclear Eng. Dept.

Mississippi State, MS 39762
No. of

Copies

Oregon State University

Attn: Dr. Gordon M. Reistad

Mechanical Engineering Dept.

Corvallis, OR 97331

3 Oregon State University

Attn: J. Zaworski

Mechanical Engineering Dept.

Corvallis, OR 97331

The George W. Woodruff School of Mechanical Engineering Attn: Dr. William J. Wepfer Georgia Institute of Technology 225 North Ave. NW

Atlanta, GA 30332

ONSITE

DOE Richland Operations Office

D. R. Segna

20 Pacific Northwest Laboratory

M. K. Drost, K5-21 (10)

B. M. Johnson, $\mathrm{k} 5-25$

L. D. Kannberg, K5-21

C. W. Stewart, $K 5-25$

G. M. Stokes, K2-51

Technical Report Files (5)

Publishing Coordination 


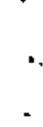

